\title{
PERFORMANCE AND EMISSION CHARACTERISTICS ON GLOW PLUG HOT SURFACE IGNITION C.I. ENGINE USING ETHANOL AS FUEL WITH ADDITIVE
}

\author{
B. Omprakash ${ }^{1}$, B. Durga Prasad ${ }^{2}$ \\ ${ }^{1}$ Assistant Professor, Mechanical Engineering Department, JNTUA College of Engineering, Ananthapuramu, A.P, \\ India \\ ${ }^{2}$ Professor, Mechanical Engineering department, JNTUA College of Engineering, Ananthapuramu, A.P, India
}

\begin{abstract}
The concept of using alcohol fuels as alternative to diesel fuel in diesel engine is recent one. The scarcity of transportation petroleum fuels due to the fast depletion of the petroleum deposits and frequent rise in their costs in the international market have spurred many efforts to find alternatives. Alcohols were quickly recognized as prime candidates to displace or replace high octane petroleum fuels. Innovative thinking led to find varies techniques by which alcohol can be used as fuel in diesel engine. Amongst the fuel alternative proposed, the most favourest ones are methanol and ethanol. The specific tendency of alcohols to ignite easily from a hot surface makes it suitable to ignite in a diesel engine by different methods. The advantage of this property of alcohols enables to design and construct a new type of engine called surface ignition engine. Methanol and ethanol are very susceptible to surface ignition, this method is very suitable for these fuels. The hot surfaces which, can be used in surface ignition engine are electrically heated glow plug with hot surface. Hence present research work carries the experimental investigation on glow plug hot surface ignition engine, by adding different additives with methanol and ethanol as fuels, with an objective to find the best one performance, emission and compression parameters.
\end{abstract}

Keywords: GHSI, Ethanol, Low Heat Rejection, PSZ, Additive (Iso amyl nitrate).

\section{INTRODUCTION}

Transportation fuels, which can be derived from non-crude oil resources, include Methanol, Ethanol, Natural gas, Liquefied petroleum gases (LPG), and Hydrocarbons (from coal and shale). Each of these fuels has advantages and disadvantages associated with cost, availability, environmental impact, engine and vehicle modifications required safety, and customer acceptance. Ethanol has been widely used as gasohol, a mixture of $90 \%$ gasoline and $10 \%$ Methanol, as transportation fuels for pickup trucks, especially in the Southwest US. LPG has been used as an alternative fuel for a longer continuous period of time than either Methanol or Natural gas. Although no effort has been made in the US by vehicle manufacturers to develop an optimized LPG engine, Chrysler [24] Canda has developed an engine for use in an LPG - fueled van. The US Department of Energy (DOE) is presently supporting research in this area.

\section{EXPERIMENTAL WORK}

The single cylinder, four strokes $5.2 \mathrm{~kW}$ Kirloskar, watercooled DI diesel engine with a bore of $87.5 \mathrm{~mm}$ and stroke of $110 \mathrm{~mm}$ and a compression ratio of $17: 1$ is used for the experiment. The engine load is applied with eddy current dynamometer. For the reduction of heat to the cooling water the plain engine is modified by fitting with a PSZ coated cylinder head and liner. Then the existing aluminum piston is replaced by a copper piston crown with an air gap. These air gap surfaces are coated with PSZ. These tests are conducted with Methanol as fuel in GHSI engines as usual.

The experiments are carried out on the plain engine with the copper piston crown material with or without additive(Iso amyl nitrate) on GHSI engine and in LHR engine using Methanol as fuel to determine the performance, emissions and the combustion parameters which are presented below.

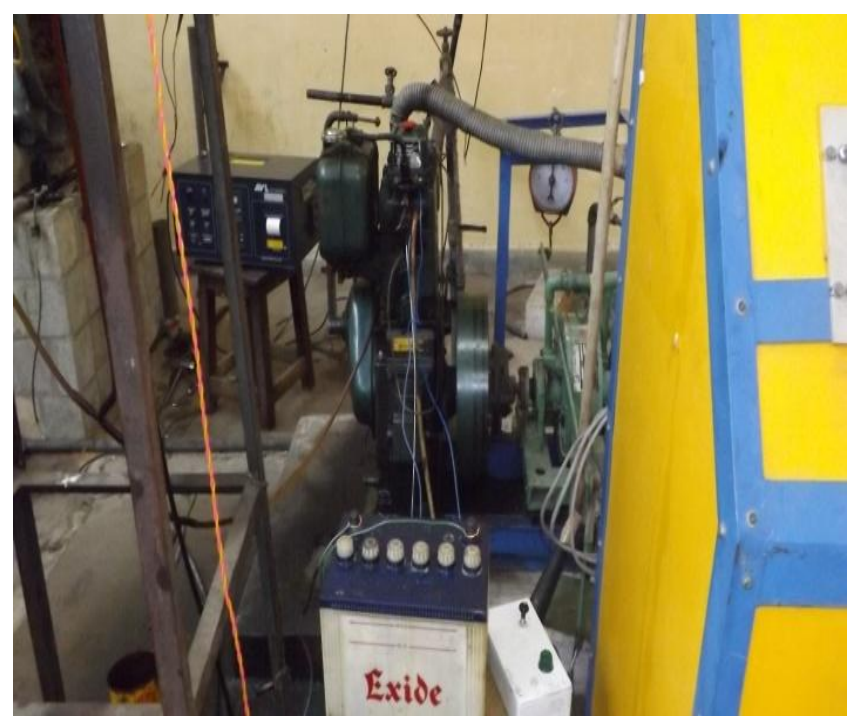

Fig 1 Experimental setup of GHSI LHR Engine Test rig 


\section{RESULTS AND DISCUSSION}

\subsection{Ethanol Operation in GHSI LHR Engine}

The experiments are carried out on the plain engine on the copper piston crown material with or without additive(Iso amyl nitrate) on GHSI engine and in LHR engine using Ethanol as fuel to determine the performance, emissions and the combustion parameters, which are presented below.

Figure.1.2. shows the variation of brake thermal efficiency with brake power output.

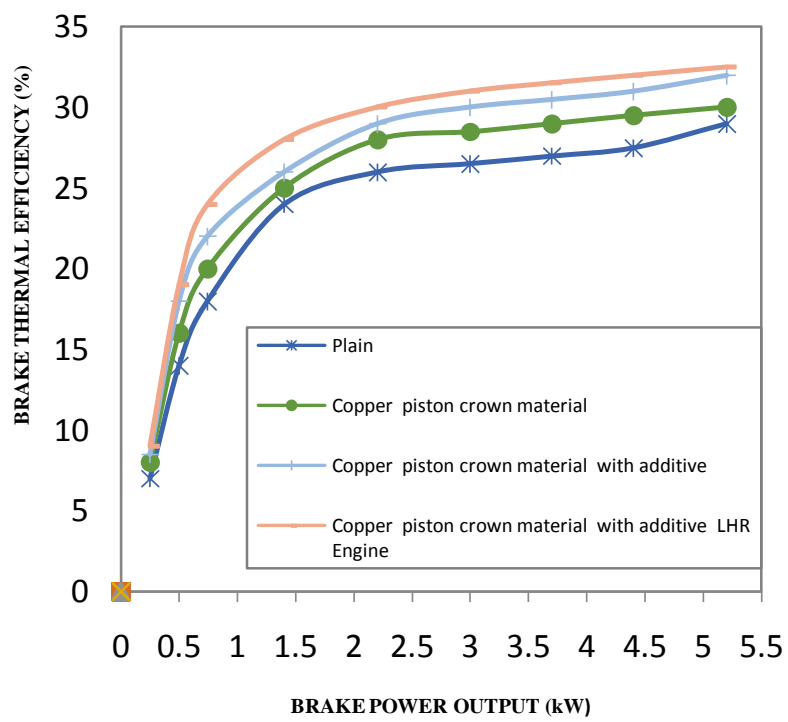

Over a wide range of operation, the brake thermal efficiency of copper piston crown material GHSI with additive shows maximum efficiency. The copper piston crown material GHSI engine with and without additive(Iso amyl nitrate) has brake thermal efficiencies closely following the plain GHSI engine. As compared to other above configurations, the plain GHSI engine indicates minimum performance. The copper piston crown material GHSI engine with additive (Iso amyl nitrate) in LHR engine has a percentage improvement of 5\% at rated load over plain engine, which can be attributed to the positive ignition of the injected Ethanol spray by the glow plug under all conditions. The ability of the LHR engine to prepare the injected Ethanol spray into readily combustible mixture in very short time is multiplied by the improvement with glow plug with copper piston crown material with additive (Iso amyl nitrate).

The variation of peak pressure with brake power output is shown in figure 1.3.

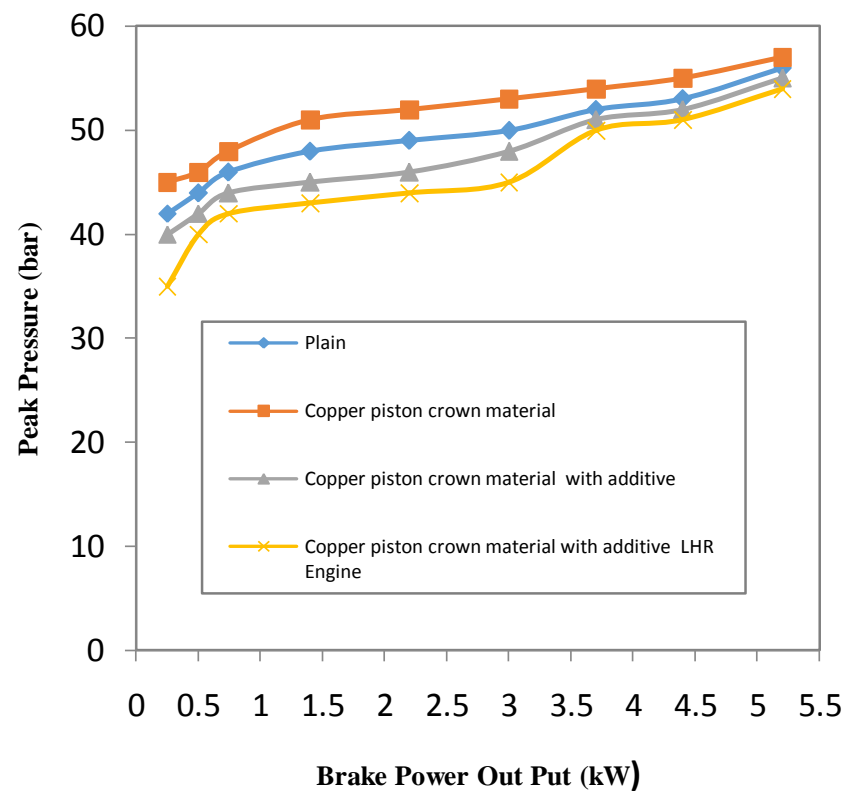

The peak pressure of copper piston crown material GHSI engine with additive(Iso amyl nitrate) is higher than plain GHSI engine in LHR engine. At rated load, the copper piston crown material GHSI engine shows high peak pressure of 58 bar with additive(Iso amyl nitrate).

The variation of maximum rate of pressure rise with brake power output is shown in figure 1.4.

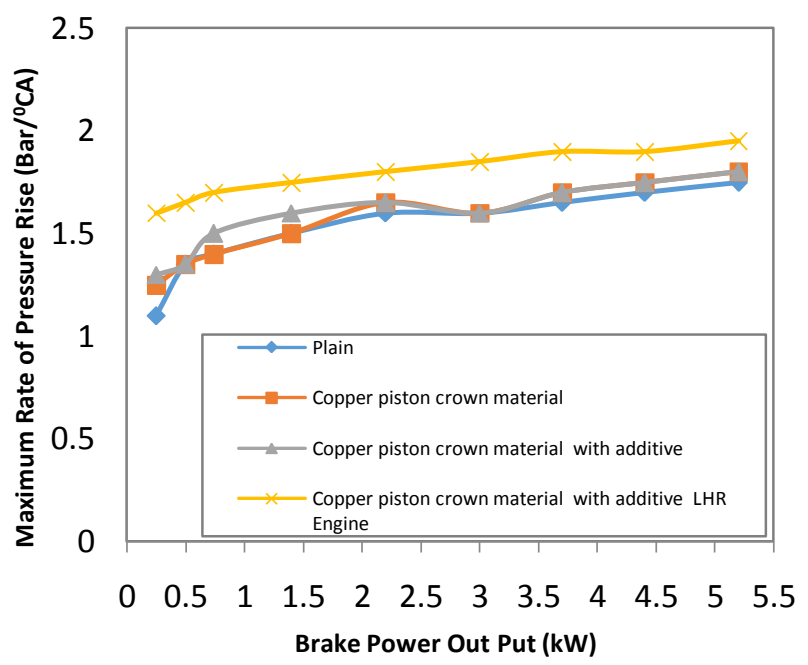

The maximum rate of pressure rises for plain GHSI engine is found to be lower than the copper piston crown material GHSI engine with additive(Iso amyl nitrate) in LHR engine. At rated speed, it is the highest for copper piston crown material CHSI engine with additive in LHR engine and is $40 \%$.

The variation of ignition delay with brake power output is illustrated in figure 1.5 . 


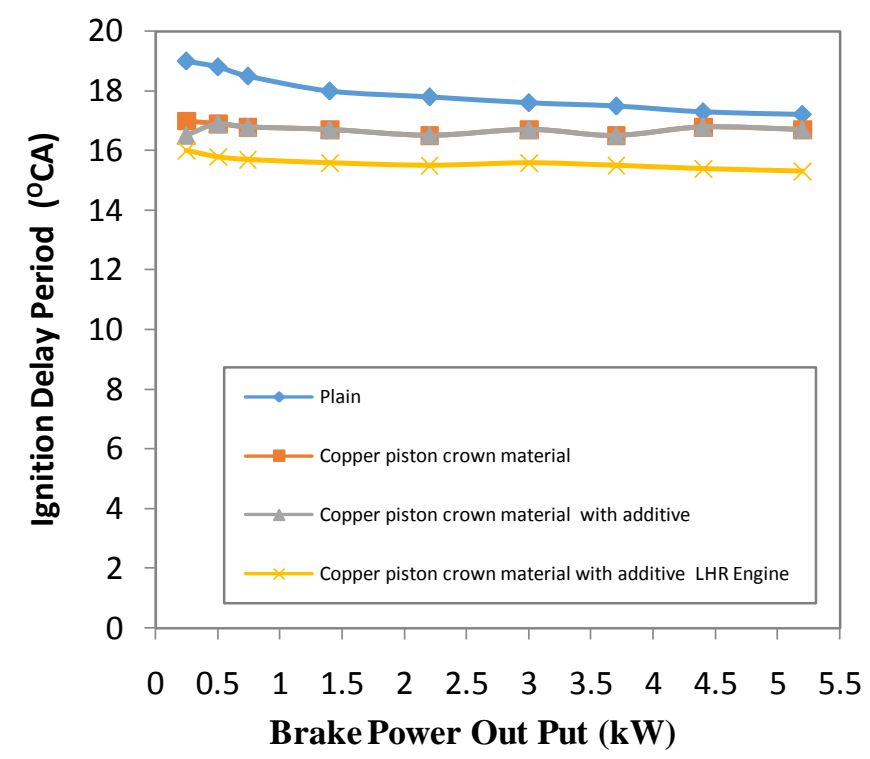

The plain GHSI engine has the highest ignition delay. The reduction in ignition delay over plain GHSI engine for copper piston crown material GHSI engine with additive in LHR engine is $2.6^{\circ} \mathrm{CA}$, which is due to hotter combustion chamber of LHR engine. As compared to plain engine the operation of LHR engine is smoother.

Figure 1.6 shows the variation of combustion duration with brake power output.

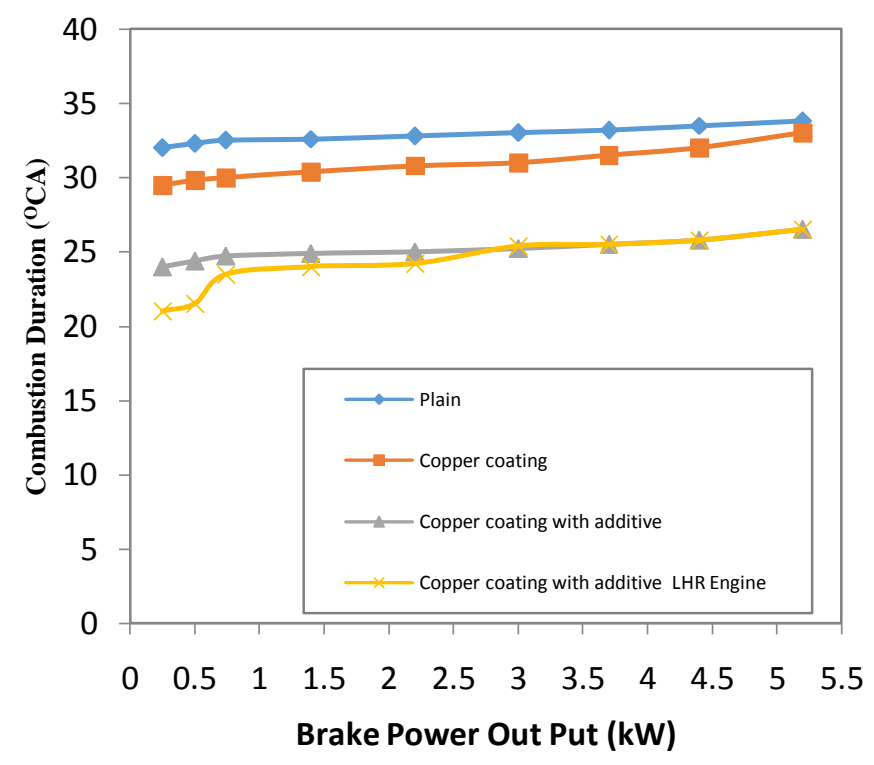

The variation in combustion duration between various modes of operation is marginal. The shortest combustion duration is shown by copper piston crown material GHSI engine with additive(Iso amyl nitrate) in LHR engine as compared to GHSI engine. At rated load, the combustion duration of copper piston crown material GHSI engine with additive in LHR engine is shorter by $5^{\circ} \mathrm{CA}$ when compared to the plain GHSI engine.
Figure 1.7 shows HC emission levels for plain GHSI and copper piston crown material GHSI engine with additive in LHR engine.

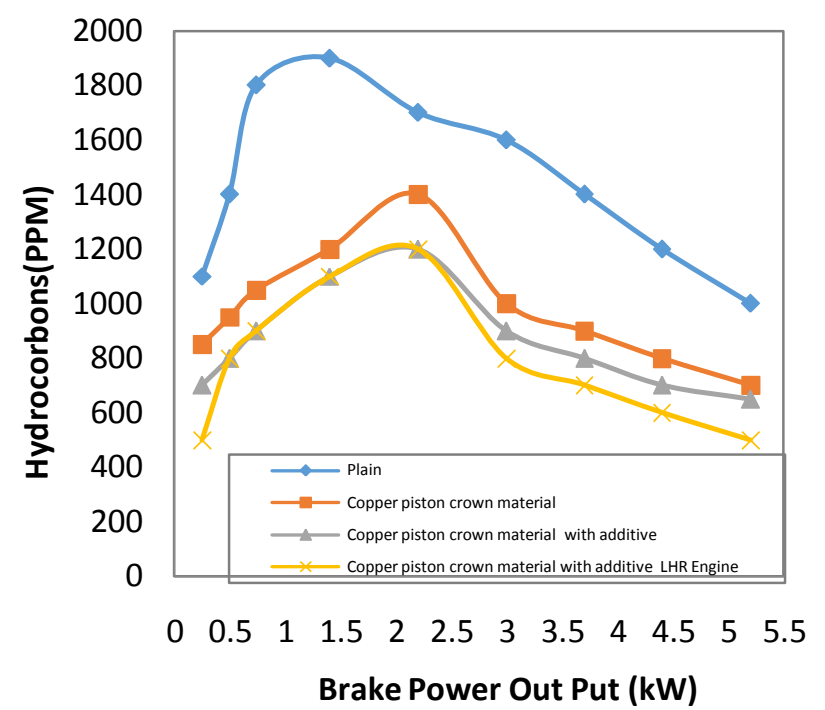

As compared to plain GHSI engine, copper piston crown material GHSI engine with additive in LHR engine shows maximum reduction in $\mathrm{HC}$ emission level. At rated load, the reduction in $\mathrm{HC}$ emission level over the corresponding plain GHSI engine is about $400 \mathrm{ppm}$.

The variation of $\mathrm{CO}$ emissions with brake power output is shown in figure 1.8 .

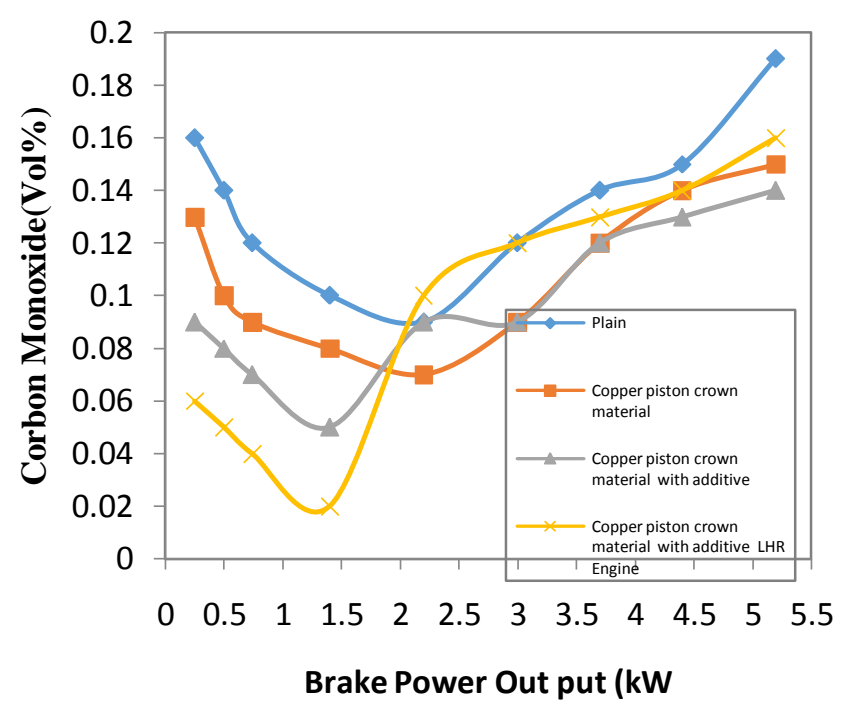

The plain GHSI engine indicates higher level of $\mathrm{CO}$ emissions when compared to copper piston crown material GHSI engine with additive(Iso amyl nitrate) in LHR engine and is about $9 \%$ by volume at rated load. The reduction is less pronounced at part loads than at rated loads.

The variation of exhaust smoke emission levels with power output is shown in figure 1.8. The smoke emissions of copper piston crown material GHSI engine with additive(Iso amyl nitrate) in LHR engine are lowest almost over the entire operating range. 


\section{CONCLUSION}

The following conclusions are drawn with Methanol operated GHSI with additive(Iso amyl nitrate) in LHR engine.

1. It is observed that due to better combustion the maximum percentage improvement for the copper piston crown material GHSI with additive(Iso amyl nitrate) in LHR engine over the plain engine is $5 \%$.

2. Reduced ignition delays, lower combustion duration, higher peak pressure and higher rates of pressure rise are noted for the copper piston crown material GHSI engine with additive in LHR engine.

3. This must be due to the better vaporization of injected fuel in a shorter time. For copper piston crown material GHSI with additive(Iso amyl nitrate) in LHR engine, the ignition delay is lower by $2.6^{0} \mathrm{CA}$.

4. The increase in peak pressure level is 58 bar, the maximum rate of pressure rise increases by $40 \%$ at rated load.

5. The combustion duration is shorter by $5^{\circ} \mathrm{CA}$. Hence copper piston crown material GHSI with additive in LHR engine is smoother.

6. It is observed that, the emission levels are lower with copper piston crown material GHSI with additive in LHR engine.

7. The LHR engine indicates lower level $\mathrm{CO}$ emissions and is about $9 \%$. The maximum reduction in $\mathrm{HC}$ emission level over the corresponding plain GHSI engine is about $400 \mathrm{ppm}$.

\section{ACKNOWLEDGMENTS}

B.OMPRAKASH, working as a Assistant Professor in the department of Mechanical Engineering, JNTUA College of engineering, Anantapuramu, Andhra Pradesh, INDIA. I completed my M.Tech in Heat Power(R \&AC) from JNT University, Anantapur, Andhra Pradesh. At present I am doing my P.hD work in the area of internal combustion engines under the guidance of Dr. B. Durga Prasad, Professor\&Head of Mechanical Engineering dept., JNT University, Anantapuramu. I published 2 articles in various national and international conferences and 5 research papers in various national and international journals.

\section{REFERENCES}

[1]. R. D. Barnes, - Effect of a supplementary fuel in turbocharged diesel engine- SAE 750469, 1975.

[2]. R. Kamo and W. Bryzik," Adiabatic Turbocompound Engine Performance Prediction", SAE 1978, paper 780068.

[3]. R. Kamo, et al," Cummins- TARADCOM Adiabatic Turbocompound Engine program", SAE 1981, Paper 810070.

[4]. Michael C. Brands," Vehicle Testing of Cummins Turbocompound Diesel Engine", SAE 1981, Paper 810073.

[5]. Ozer Can, smet Çelik ten and Nazim Usta," Effects of ethanol addition on performance and emissions of a turbocharged in direct injection Diesel engine running at different injection pressures ", SAE Technical paper,2004.
[6]. Arunachalam M, "Investigations on the performance of a diesel engine with ceramic thermal barrier coating on parts of the combustion chamber surface", Proc. of the QIP short term course on recent developments in I.C. engines, IIT, Madras, 1988.

[7]. A. Lawson, A.J. Last, A.S. Deshpande and E.W. Simmons, 'Heavy-duty truck diesel engine operation on un stabilized methanol diesel fuel emulsions', SAE Paper 810346, February 1981.

[8]. Lester C. Litchty, 'Internal Combustion Engines', McGraw Hill book co., USA, 1951.

[9]. L.R. Lilly, 'Diesel engine reference book; Butter worth and Co. (Publishers) Ltd., England, 1984.

[10]. Makihara, S., murakami, Y., Rokushima, K., Nakajima, T., and Matumoto. R., 'Ignition phenomena of methanol and methanol Isooctane blends by a hot surface', VII Int. Sympon Alcohol fuels Technology, Tokyo, japan, 1988, pp.315-320. 